УДК 7.01

DOI: $10.17223 / 22220836 / 40 / 4$

\author{
А.С. Дриккер, Е.А. Маковецкий \\ МУЗЕЙНАЯ АУРА В ЦИФРОВОМ ФОРМАТЕ
}

\begin{abstract}
Эмочиональное воздействие музейного пространства традиционно связывалось с представлением об ауре, эманации. Аура уникального экспоната всегда виделась как его естественная и несомненная принадлежность. Однако в индустриальной ичивилизации восприятие принципиально меняется. В. Беньямин объяснил эти изменения тем, что техническая репродуцируемость смывает ауру. Поскольку музейные шедевры остаются практически неизменными, а физических следов ауры обнаружить не удается, влияние репродуцируемости логично связать со зрителем. Стремительная общественная динамика деформирует его взгляд, который утрачивает способность ощутить ауру. Возможно ли «возродить» это утраченное ощущение? Надежду дают те самые цифровые технологии, что явились причиной исчезновения ауры.

Ключевые слова: аура, музей, информационно-коммуникациионые технологии.
\end{abstract}

Историческое ускорение, рост темпов культурной эволюции затронули и такой казалось бы консервативный институт, как музей. После Второй мировой войны популярность музея довольно неожиданно возрастает, а в информационную эру музей становится одним из столпов актуальной культуры. Стремительное развитие информационно-коммуникационных технологий с экспансией виртуальной реальности, активно внедряющейся практически во все аспекты жизнедеятельности, остро ставит вопрос: завершилось ли время музея-храма, который уступает дорогу «демократическому музею», или его потенциал вполне может быть востребован в новую эру?

\title{
Технолого-демократическая ревизия
}

Политика современного музея отвечает тренду глобальной демократической культуры. Сотни миллионов посетителей, новые и новые музеи, множащиеся на всех шести континентах, музейное правительство - авторитетнейший Международный совет музеев (ICOM), музеология как новое научное и образовательное направление - все эти успехи наглядно демонстрируют очевидное всемирное торжество музея. В качестве теоретического базиса такой музейной политики часто упоминается знаковая работа В. Беньямина «Произведение искусства в эпоху его технической воспроизводимости» [1]. Сегодня мощнейшее влияние ускоряющегося производствапотребления, цифровых технологий, средств массовой информации и новых носителей информации на культуру и искусство - одна из наиболее модных тем [2]. Привлекательность идей социальной ответственности, прогрессистских представлений не вызывает сомнений. На базе этих идей рождается целое направление - «новая музеология» [3], новые теории и практики «постмузея» [4], «музея участия» [5], фокусирующихся на рядовом посетителе с его интересами, на активном вовлечении сообществ в решение актуальных

\footnotetext{
${ }^{1}$ Исследование выполнено в рамках проекта РФФИ № 19-011-00371.
} 
проблем. Однако безальтернативный курс на демократизацию, который оставляет классическому музею место скорее реликвии, кажется не совсем убедительным. Культура весьма экономна, она не отбрасывает ценнейшие достижения в связи с сезонной сменой моды.

Заметим, что внимание Беньямина обращено на то, как социальнотехнологические изменения повлияли на восприятие масс, в то время как его современник советский психолог Л. Выготский (также со свойственных времени социальных позиций) концентрируется на психологических аспектах восприятия [6]. Быть может, в контексте актуальной цифровой культуры социально-аналитический подход продуктивно совместить с психологическим?

Особый духовный мир музея испокон веков создавался посредством исключительно материальных объектов (будь то скульптура Микеланджело, бедренная кость Homo erectus или кристалл полевого шпата). Материальность для музейного предмета - базисная характеристика. Музейный экспонат - это «материальный остаток, сознательно выделенный из среды ввиду его особой ценности и предназначенный для постоянного хранения» [7. C. 176], «источник материализованный, фиксированный, имеющий определенную совокупность признаков: содержание, материал, форму, устройство, размер, вес, цвет» [8. С. 6], «материальное свидетельство явлений в природе, культуре и обществе» [9. С. 23].

Сам статус музейного экспоната подразумевает его уникальность, «врожденную», как у шедевра Леонардо, или определенную коллекционным отбором и статусом собрания. Музейное пространство маркирует как избранный экземпляр и гравюру тиражной серии, и осколок керамического сосуда, и даже телефонный аппарат, собранный на поточной линии, за счет того особого места в культурном ландшафте, которое выявляется экспозицией.

В музее (музее-храме, каким он явился в конце XVIII в.) экспонат обретает сакральность подобно любым деталям ритуала и храмового интерьера. В силу чего аура, эманация музейного предмета (как оригинала, так и копии) воспринимается как его органичная священная принадлежность, несмотря на то, что утверждается музейная институция в эпоху уже достаточно безбожную.

В. Беньямин, анализируя культурную динамику XX в., в стремительных демократических трансформациях художественных процессов, искусства обнаруживает важнейшее, принципиальное технологическое влияние: «С появлением различных методов технической репродукции произведения искусства его экспозиционные возможности выросли в таком огромном объеме, что количественный сдвиг в балансе его полюсов переходит, как в первобытную эпоху, в качественное изменение его природы» [1. С. 19]. Репродуцируемость смывает ауру произведения, растворяя сначала сакральные, а следом и ритуальные основания.

Те экспозиционные возможности, которые Беньямин обсуждал почти столетие назад, совершенно несопоставимы с нынешними, явившимися в эпоху Интернета. На сегодняшний день, прогрессивно ускоряясь час от часа, процесс близок к очевидному апогею. Доступность массовых репродукций всех видов (прежде всего, экранных), сильнейшим образом девальвировала сакральность музейного пространства. Музейные храмы сдают позиции и трансформируются в просветительско-развлекательные центры. Модифика- 
ции музея могут протекать крайне радикально, как в Sony Museum (Токио), музеях Гугенхейма (Нью-Йорке и Бильбао). Или внешне не столь заметно, но неуклонно: Лувр, более столетия отвергавший любые попытки вторжения современного искусства, уже отказался от прежней непреклонной позиции, Эрмитаж снимает античные скульптуры с пьедесталов, чтобы посетитель, оказавшись вровень с ними, не ощущал репрессивность культуры. Наступление виртуальности ставит принципиальный вопрос: остается ли в цифровом обществе место для музея в традиционном представлении? И как быть с проблемой пресловутой музейной ауры: то ли забыть о ней как о чем-то допотопном, вроде верований первобытных предков, то ли, напротив, попытаться возродить, увидев в новом свете?

\section{Аура и носитель информации}

Присутствие ауры в музее прошедших столетий не вызывает сомнений, оно подтверждается множеством авторитетных свидетельств. К примеру, великие русские писатели Н.В. Гоголь и Ф.М. Достоевский, тонко чувствовавшие изобразительное искусство (что отличает совсем не каждого мастера слова), отмечали удивительное, незабываемое в течение всей жизни впечатление, произведенное на них «Сикстинской Мадонной». А вот как пишет о встрече с «Мадонной» русский поэт Василий Андреевич Жуковский: «Это не картина, а видение: чем долее глядишь, тем живее уверяешься, что перед тобою что-то неестественное происходит... Здесь душа живописца... передала холстине то чудо, которое во внутренности ее совершилось. Не видав оригинала, я хотел купить себе в Дрездене этот эстамп; но, увидев, не захотел и посмотреть на него: он, можно сказать, оскорбляет святыню воспоминания...» (письмо В.А. Жуковского о посещении Дрезденской галереи, написанное в 1821 г. из Германии) [10. С. 179-186].

Можно, конечно, отнести этот пассаж на счет личной чувствительности поэта-романтика, а отзывы Гоголя и Достоевского объяснять спецификой нервной организации, особой впечатлительностью. Или же предположить, что после того как «бог умер», аура истончается и исчезает, что в динамичном мире расширенного воспроизводства утрачивается способность ощутить ауру.

Взгляды и мнения по поводу ауры и ее роли явлены целым спектром как в музейной, художественной среде, так и в зрительской. Аура предполагает наличие у оригинала неких уникальных, не поддающихся техническому репродуцированию свойств. Именно эти качества дают возможность экстрасенсорно воспринимать душевные вибрации автора, ощущать эманацию произведения. Идеи энергетического воздействия особенно органичны и популярны в исполнительском искусстве. К.С. Станиславский писал об электрическом заряде, об индукции, порождаемой переживаниями актера: «Если насытить жизнь тела чувством, как аккумулятор электричеством, то эмоции закрепляются в телесном, хорошо ощутимом физическом действии» [11. С. 224-225].

Способность музейных собраний вызывать сильнейшее «энергетическое» воздействие, мощное аффективное переживание не вызывает сомнений. Однако попытки обнаружить локализацию ауры, ее материальные следы, индуцирующие загадочное поле и определяющие удивительное воздействие музейных экспонатов на зрителя, ни к чему не приводят [12] (и, вероятно, никогда не приведут). 
Если с молекулярной структурой мрамора, тронутого рукой гения, с магнетическим звучанием голоса Шаляпина, с мумифицированными останками фараона можно связать неуловимые таинственные флюиды, то стоит перейти к «техническим» видам искусства, например к кино, - и места для тайны не остается, теория эманации теряет всякую убедительность. Кинопленка не хранит никакой «тонкой» энергии. С целлулоидной перфорированной ленты проецируются двадцать четыре кадра в секунду и считывается звук - больше на ней нет ничего. В тиражном издании «Фауста» Гете с помощью литер воспроизводятся только буквы, из коих слагаются слова и фразы. Кроме многослойных и многосложных отражающих поверхностей ничего более не обнаружить в художественном полотне...

Произведение обладает потенциалом, скрытой энергией, но для того чтобы античная скульптура или оперная ария «состоялись» - вызвали глубокие, сильные переживания, они должны встретить своего зрителя. Информация не имеет ценности сама по себе, ценность проявляется только тогда, когда сообщение воспринимается адресатом, способным расшифровать, понять, почувствовать. Эмоции актера накапливаются, аккумулируются (как отмечал Станиславский), но раскроется их потенциал только с откликом зрителя. С. Эйзенштейн отмечал, что энергию для художественного аффекта зритель приносит с собой [13].

«Давид» Микеланджело на протяжении столетий оставался практически неизменным, а вот восприятие в XXI в. меняется принципиально. В напряженном ритме прагматичной жизни, в мощном потоке рекламных впечатлений зритель не успевает, а следом и не хочет сосредоточиться: «Современный человек... не может более вести созерцательный образ жизни, он должен... работать больше и лучше, чем все другие... чистое созерцание в модерную эпоху, и, прежде всего, в наше столетие, было подвергнуто полной девальвации» [14]. В эпоху технического воспроизводства воздействию подвергается, в первую очередь, не произведение с его эманацией, а музейная атмосфера, теряющая озон, без которого воображение зрителя тускнеет, а аура гаснет.

Отсутствие вещественных следов ауры, ее современное «исчезновение» дают основание заключить, что произведение в своем материальном воплощении - это только медиа, посредник между творческим импульсом, проектом художника и зрителем. Современные технологии позволяют любую форму, всякого посредника (например, акустические волны, с помощью которых исполнитель доносит до слушателя чувства и переживания композитора) практически идеально повторить тем или иным способом. Все, что доступно уху или глазу, в состоянии воспроизвести звукозаписывающие или сканирующие устройства. Копия уже проходит тест Тьюринга - становится (даже для эксперта) неотличимой от оригинала, но на ауре это никак не сказывается. К тому же сегодня проблема копии и оригинала переходит в иную плоскость, поскольку свершается нечто недавно совершенно непредставимое.

Технологии виртуальной реальности сводят на нет возможности различения «объективного» и иллюзорного восприятия, а технобиология размывает границы между «настоящей» жизнью и ее симуляцией. Музей с его уникальными коллекциями, бесценными оригиналами сталкивается с серьезнейшей конкуренцией. Механизмы виртуальной, дополненной реаль- 
ности угрожают уже в достаточно обозримом будущем обеспечить зрителя комплексом полноценных ощущений персонального свидания с экспонатом. Дематериализация музейного предмета - этап еще более значительный, чем появление технических аппаратов для совершенного дублирования и сканирования.

\section{Поиски ауры в демократической среде}

Сегодня казавшаяся недавно незыблемой позиция музейного экспоната, самой музейной субстанции поколеблена: весь культурный ландшафт, коммуникации и восприятие демократического зрителя, который может увидеть, скопировать, скачать любой шедевр, радикально изменились. Что же происходит сегодня с музеем, который также, естественно, захвачен общей динамикой, каковы его перспективы?

Обратимся к уникальному экспонату с его аурой, определявшей суть и смысл присутствия музея в культуре. Поскольку никаких материальных подтверждений независимого существования ауры, как уже отмечалось, не удается обнаружить даже с помощью спектрального анализа, то, вероятно, следует изменить направление поисков.

Поиски эти имеют длинную историю. Такой авторитетнейший практик, как Л.Н. Толстой, в работе «Что такое искусство?» [15] уже более века назад, по сути, поставил вопрос об ауре. Блестящее исследование Л.С. Выготского «Психология искусства» созвучно толстовскому, несмотря на принципиально иной подход, установки и жесткую критику выводов Толстого. Выготский пишет: «Мы смотрим на художественное произведение как на совокупность эстетических знаков, направленных к тому, чтобы возбудить в людях эмоции, и пытаемся на основании анализа этих знаков воссоздать соответствующие им эмоции» [6]. Если вслед за Выготским (и Львом Толстым) за эстетическими знаками увидеть авторские переживания, то оригиналом следует счесть не типографский или даже рукописный текст поэмы, не гениальное исполнение пианистом музыки Моцарта или Шуберта, а некоторую эмоциональнознаковую проекцию автора, его духовного озарения. К этому оригиналу и порождаемой им вдохновляющей ауре всегда было непросто пробиться. Для нынешнего восприятия, для демократического зрителя, вооруженного самыми современными технологиями, этот оригинал с его аурой оказался совсем малодоступен. Вероятно, создать условия, возможность приблизиться к нему - задача для музея не менее важная, чем наращивание пропускной способности.

«Новая музеология», политика ICОМ ориентируют современный музей прежде всего на службу посетителям, всему человечеству. И эта генеральная линия получает полную поддержку снизу. Служение обществу, приобщение к культурным богатствам, удовлетворение запроса широких зрительских кругов - цель достойная, которую следует всячески приветствовать. Однако, включаясь в этот массовый процесс и обретая новые черты, музей явственно редуцируется. Благородная миссия ведет к очевидным издержкам. В самом шумном музее мира - Чикагском музее науки и техники [16], при всех его достоинствах, обнаружить ауру не удастся.

Конечно, некая скудость благополучной жизни, эмоциональный дефицит в техногенном мире ощущаются достаточно остро, и это необходимо компенсировать. Но помимо количества впечатлений существенна их глубина, каче- 
ство. Пока человек сохраняет свою природу и нуждается в ощущениях и переживаниях, порождаемых предметным культурно-природным миром, не меньше, чем в пище и воде, музей остается тем редким местом, в котором впечатления могут озаряться аурой - специфичным проявлением, отражением творческого начала.

Хотя наблюдается это свечение все реже. В чем причина явно недостаточной (несмотря на громкие и небезосновательно победные реляции) эффективности музея? Она связана с языковой проблемой - центральной для $\mathrm{XX}$ в. Осмысление этой проблемы стимулирует развитие на музейной почве семиотического подхода. Наиболее популярные его вариации - это многообразные попытки (от пионерских [17] до современных [18], по-прежнему не самых продуктивных) моделировать музейные коммуникации, выявить «язык музея как универсальной моделирующей системы» [19]. Экспозиция «высказывается» на визуальном языке иконических, изобразительных знаков. Казалось бы, язык изобразительных знаков - самый понятный и доступный. Однако своей простотой он сбивает неискушенного зрителя на упрощенный, поверхностный контакт. Сознание, мигом считывая информацию и опознавая объект, не задерживает на нем внимание и разгружает память, фиксируя лишь общий контур.

Музей же требует иного взгляда - пристального, сосредоточенного, свойственного отношению «Я - Ты» [20], отношению личностному, эмоциональному. Взгляд зрителя должен уподобиться взгляду художника, который не копирует объекты, как фотоаппарат или сканер, но выражает интимные взаимоотношения с субъектом, будь то пейзаж Коро или «Стул» Ван Гога. Тот ореол, что вдохновляет, увлекает зрителя в настоящем музее (историческом, техническом, зоологическом, художественном...), рождается только в подобном пытливом, участливом смотрении. Но каким же образом пробудить этот особенный взгляд зрителя?

\section{Цифровые надежды и перспективы}

В нынешнем информационном обществе отношение к цифровым технологиям представляет одну из современных вариаций традиционной оппозиции новаторов и консерваторов. Первые, как всегда уповая на прогресс, ожидают разрешения всех проблем за счет наращивания скорости передачи информации. Хотя, пожалуй, острейший вопрос сегодня - отнюдь не мегабайты в секунду. Консерваторы, концентрируясь на изъянах общества массового потребления и коммуникаций, связывают надежды с идеологической реабилитацией восприятия, свойственного музейной, художественной среде прошлых веков. Однако громогласные призывы к возрождению классического наследия, возвращению традиций абсолютно несостоятельны и не имеют сколько-нибудь внятных перспектив. В технологически унифицированной, гомогенной демократической культуре эти лозунги являют лишь один из ее массовых трендов.

Какой-либо реальный потенциал для возрождения музейной ауры сегодня можно искать лишь в той самой технологии, что ее похоронила. Однако не в тех, с одной стороны, поразительных, новаторских, с другой - уже абсолютно стандартных аппаратно-программных возможностях, которые, расширяя, обогащая среду, не только не развивают психические реакции, не обога- 
щают восприимчивость, но зачастую даже упрощают, притупляют их. Если говорить не о привлечении толп туристов (актуальная цивилизация и так предлагает множество развлечений), а о воссоздании особой музейной атмосферы, то следует подумать о чем-то более серьезном, нежели компьютерные шоу, сети и клубы друзей музея или массовые радения в «Ночь музеев». Современные технологии можно использовать не только в качестве забавы для скучающего туриста. Их потенциал больше того, что востребован в образовательных, просветительских программах и продуктивно используется для расширения кругозора, пополнения культурного багажа.

Цифровое вооружение: наушники, шлемы, контактные линзы (прототипы iOptik) - уже сегодня способно настроить, подготовить зрителя к встрече с музеем: создать условия для концентрации, сенсорной депривации. Но следующий, технолого-психологический, этап еще сложнее. Внешние впечатления в процессе оформления образа тесно взаимодействуют с воспоминаниями, с личным опытом. Только в этом опыте можно найти стимулы, способные пробудить интерес, активировать внимание зрителя. Но как, обратившись к памяти, связать интерес посетителя краеведческого музея в Зарайске с шерстистым носорогом, бродившим по холмам на границе Московской и Рязанской областей? Как включить ассоциации, которые поспособствуют тому, чтобы посредством пластмассового корпуса «Спидолы» - транзисторного приемника (предела мечтаний советского человека 1960-х) - ощутить вдохновение советской эпохи «оттепели». Серьезнейшая проблема. Решение ее сегодня практически даже не ищется.

Нынешняя не читающая книг публика полнее всего выражает себя в сетевой среде, которая содержит огромное количество персональных данных пользователя. Эти данные в облачной и безоблачной среде, которыми герой нашего времени не в состоянии воспользоваться, - прекрасная база для анализа личного опыта, выявления и отбора предпочтений, для поиска корреляций вкусов и познаний зрителя и тех музейных впечатлений, которые его ожидают в экспозиции.

Программная инициация ассоциативных связей - весьма перспективный путь к тому, чтобы стимулировать личностный выбор как шаг к взрослению. Подобная особая «виртуальная» поддержка, ориентированная на уровень и пристрастия актуального потребителя-пользователя, в состоянии существенно влиять на восприятие, вызывать непосредственный интерес, яркие эмоции, оставляющие след в памяти, а потому способствующие росту. И гаджет, без которого музейного посетителя теперь нельзя представить, окажется здесь, возможно, крайне эффективным орудием.

Одна из серьезнейших сегодняшних проблем - эмоциональное упрощение, стандартизация в комфортной, сытой среде информационного общества. Однако именно бездушная дематериализация и дигитализация, все более совершенно воссоздавая в цифровом формате византийскую икону, бумеранг австралийского аборигена или скелет диплодока, открывает возможность для обретения посетителем в музее утраченного пристального внимания, участливого видения, которому открывается аура.

Период фантастического технологического прогресса отделяет нас от времени создания «Произведения искусства в эпоху его технической воспро- 
изводимости», но, как и столетие назад, «общество еще не созрело для того, чтобы превратить технику в свой инструмент, ... техника еще недостаточно развита для того, чтобы справиться со стихийными силами общества» [1. С. 63]. Однако поиски «взаимопонимания» - пожалуй, единственный реалистичный путь, который может привести к развитию демократического зрителя.

Теперь остается ждать «эмоционального прогресса» доступных программных средств, которые, вырабатывая у пользователя устойчивые рефлексы, смогут (хочется верить) повлиять на его восприимчивость, впечатлительность, эстетическую чуткость, что позволит (конечно, не каждому, что совсем не обязательно) обнаружить в музее, традиционном или голографическом, вдохновляющий оригинал.

\section{Лumepamypa}

1. Беньямин В. Произведение искусства в эпоху его технической воспроизводимости // Избранные эссе. М. : Медиум, 1996. С. 15-65.

2. Маклюэн М. Понимание медиа: внешие расширения человека. М. ; Жуковский : КАНОН-пресс-Ц : Кучково поле, 2003. 464 с.

3. Vergo P. Introduction// New Museology. London : Reaktion Book, 1989. P. 1-5.

4. Hooper-Greenhill E. Museums and the Interpretation of Visual Culture. London : Routledge, 2000. 195 p.

5. Simon N. The Participatory Museum. 2010. URL: http://www.participatorymuseum.org/preface/ (дата обращения: 26.07.2019).

6. Выготский Л.С. Психология искусства. М. : Искусство, 1968. 572 с.

7. Разгон А.М. Музейный предмет как исторический источник // Проблемы источниковедения истории СССР и специальных исторических дисциплин: статьи и материалы. М. : Наука, 1984. C. $174-183$.

8. Финягина Н.П. Изучение музейных предметов современного периода в исторических и историко-революционных музеях. М. : Центральный музей Революции СССР, 1978. 72 с.

9. Шляхтина Л.М., Фокин С.В. Основы музейного дела: учеб. пособие для студентов педагогических и гуманитарных вузов. СПб. : СпецЛит, 2000. $160 \mathrm{c}$.

10. Жуковский В.А. Эстетика и критика. М. : Искусство, 1985. $431 \mathrm{c}$

11. Станиславский К.С. Работа актера над ролью // Собр. соч.: в 8 т. М. : Искусство, 1957. T. $4.477 \mathrm{c}$.

12. Дриккер А.С. «Энергетика» художественного воздействия: информационный анализ // Человек. 2006. № 6. С. 21-34.

13. Эйзенштейн С.М. «Одолжайтесь!» // Собр.соч.: в 6 т. М. : Искусство, 1964. Т. 2. С. 60 81.

14. Гройс Б. Медиаискусство в музеe. URL: http://anthropology.ru/ru/texts/groys/mediart.html (дата обращения: 27.08.2019).

15. Толстой Л.Н. Что такое искусство? // Статьи, письма, дневники. М. : Современник, 1985. $592 \mathrm{c}$.

16. Хадсон К. Влиятельные музеи. Новосибирск : Сибирский хронограф, 2001. 194 с.

17. Cameron D. A Viewpoint: The Museum as a Communications System and Implications for Museum Education // Curator. 1968. Vol. 11, № 1. P. 33-40.

18. Hooper-Greenhill E. Museum, Media, Message (Museum Meanings). London; New York: Routledge, 2013. $316 \mathrm{p}$.

19. Никишин Н.А. «Язык музея» как универсальная моделирующая система музейной деятельности // Музееведение. Проблемы культурной коммуникации в музейной деятельности: сб. науч. тр. М. : НИИ Культуры, 1989. С. 7-15.

20. Франкфорт Г., Уилсон Дж., Якобсон Т. В преддверии философии. Духовные искания древнего человека. М. : ГРВЛ, 1984. 236 с.

Alexander S. Drikker, St. Petersburg State University (St. Petersburg, Russian Federation).

E-mail; asdrikker@mail.ru

Eugene A. Makovetsky, St. Petersburg State University, (St. Petersburg, Russian Federation).

E-mail: evmak@yandex.ru 
Vestnik Tomskogo gosudarstvennogo universiteta. Kul'turologiya i iskusstvovedeniye - Tomsk State University Journal of Cultural Studies and Art History, 2020, 40, pp. 49-58.

DOI: $10.17223 / 2220836 / 40 / 4$

MUSEUM AURA IN A DIGITAL FORMAT

Keywords: aura; museum; information and communication technologies.

In conditions of rough social changes and of ICT of development a museum-temple gives way to modern post-museum. Whether the museum-temple era came to end, or its potential can be demanded? In search of the answer, combining the social-analitical view (Benjamin) with a psychological analysis (Vygotsky), we will address a question of aura which traditionally defined emotional influence of museum exposition.

Since moment when Benjamin noted that technical reproduction washes away aura, a scales of high-quality reproduction in network environment grew in thousands times and decisively devaluated sacrality of a museum space. Besides a democratic museum is guided by inquiry of a mass visitor with his specific perception.

An ability of museum collections to cause the strongest "power" influence, powerful passions does not raise doubts. However, attempts to find the concrete localization, material traces inducing a mysterious field and defining surprising impact on a viewer do not lead to anything. In that case it is more logical to connect a disappearance of aura with a viewer. Author's creation, museum exhibit "will not take place", without having met the viewer, his response. Art passion, emotional expenditure are provided not with external influence, but by himself viewer, his mental energy and experience. If following Vygotsky behind esthetic signs it can see author's experiences, then a suit of Eskimo and a painting - only certain sign-emotional display of internal insight of the author - of the original. A masterpiece, an exhibit are only a mediator between the viewer and the author.

A museum visitor on an exposition uses visual language, reading clear and available graphic signs. However a museum demands not reading of information, but a contemplate, concentrated look lost in rational acceleration. Whether it is possible to revive this look and aura? Digital technologies which were a reason of disappearance of aura give a such hope.

ICT technologies can be used not only as an entertainment for a bored tourist. Their potential is more that potential that is demanded in educational, educational programs. Only relying on experience and interests of viewer it is possible to adjust his on meeting with museum, with art. Experience and inquiries of the modern visitor - the network user - most full of are reflected in an array of network data. The analysis of these data (preferences) creates base to find connection of personal tastes and khowledge with those impressions which museum can offer.

Similar programming of associations, special virtual assistance can influence perception, initiating interest, bright emotions which leave marks in memory and promote growing. Perhaps, a viewer supported by "emotional" program progress will find aura in museum again.

\section{References}

1. Benjamin, W. (1996) Izbrannye esse [Selected Essays]. Translated from English. Moscow: Medium. pp. 15-65.

2. McLuhan, M. (2003) Ponimanie media: vneshie rasshireniya cheloveka [Understanding Media: The Extensions of Man]. Translated from English. Moscow; Zhukovsky: KANON-press-Ts: Kuchkovo pole.

3. Vergo, P. (1989) New Museology. London: Reaktion Book. pp. 1-5.

4. Hooper-Greenhill, E. (2000) Museums and the Interpretation of Visual Culture. London: Routledge.

5. Simon, N. (2010) The Participatory Museum. 2010. [Online] Available from: http://www.participatorymuseum.org/pre-face/ (Accessed: 26th July 2019).

6. Vygotsky, L.S. (1968) Psikhologiya iskusstva [Psychology of Art]. Moscow: Iskusstvo.

7. Razgon, A.M. (1984) Muzeynyy predmet kak istoricheskiy istochnik [The museum item as a historical source]. In: Kovalchenko, I.D. (ed.) Problemy istochnikovedeniya istorii SSSR i spetsial'nykh istoricheskikh distsiplin [Problems of the USSR History Source Studies and Special Historical Disciplines]. Moscow: Nauka. pp. 174-183.

8. Finyagina, N.P. (1978) Izuchenie muzeynykh predmetov sovremennogo perioda $v$ istoricheskikh i istoriko-revolyutsionnykh muzeyakh [The study of museum items of the modern period in historical and historical-revolutionary museums]. Moscow: USSR Central Museum of the Revolution.

9. Shlyakhtina, L.M. \& Fokin, S.V. (2000) Osnovy muzeynogo dela [Fundamentals of Museum Studies]. St. Petersburg: SpetsLit. 
10. Zhukovsky, V.A. (1985) Estetika i kritika [Aesthetics and Criticism]. Moscow: Iskusstvo.

11. Stanislavsky, K.S. (1957) Sobranie sochineniy: $v 8 t$. [Collected Works: In 8 vols]. Vol. 4. Moscow: Iskusstvo.

12. Drikker, A.S. (2006) "Energetika" khudozhestvennogo vozdeystviya: informatsionnyy analiz ["Energy" of artistic impact: an information analysis]. Chelovek. 6. pp. 21-34.

13. Eisenstein, S.M. (1964) Sobranie sochineniy: v 6 t. [Collected Works: In 6 vols]. Vol. 2. Moscow: Iskusstvo. pp. 60-81.

14. Groys, B. (n.d.) Mediaiskusstvo v muzee [Media art in the museum]. [Online] Available from: http://anthropology.ru/ru/texts/groys/mediart.html (Accessed: 27th August 2019).

15. Tolstoy, L.N. (1985) Stat'i, pis'ma, dnevniki [What is art?]. Moscow: Sovremennik.

16. Hudson, K. (2001) Vliyatel'nye muzei [Influential Museums]. Translated from Enlgish by L. Motylev. Novosibirsk: Sibirskiy khronograf.

17. Cameron, D. (1968) A Viewpoint: The Museum as a Communications System and Implications for Museum Education. Curator. 11(1). pp. 33-40.

18. Hooper-Greenhill, E. (2013) Museum, Media, Message (Museum Meanings). London; New York: Routledge.

19. Nikishin, H.A. (1989) "Yazyk muzeya" kak universal'naya modeliruyushchaya sistema muzeynoy deyatel'nosti [The "Language of the Museum" as a universal modeling system of museum activity]. In: Muzeevedenie. Problemy kul'turnoy kommunikatsii v muzeynoy deyatel'nosti [Museology. Problems of Cultural Communication in Museum Activity]. Moscow: NII Kul'tury. pp. 7-15.

20. Frankfort, G., Wilson, J. \& Jacobson, T. (1984) V preddverii filosofii. Dukhovnye iskaniya drevnego cheloveka [On the Threshold of Philosophy. Spiritual Quest of Ancient Man]. Translated from English by T.N. Tolstaya. Moscow: GRVL. 